Nursing \& Healthcare International Journal ISSN: 2575-9981

\title{
Volume 2 Issue 6
}

\section{Thesis}

\section{Effect of Conflict Resolution Education on Nurse-Nurse Collaboration in a Community Hospital Setting}

\section{Mayfield L}

(3) (7) 


\title{
Effect of Conflict Resolution Education on Nurse-Nurse Collaboration in a Community Hospital Setting
}

\author{
Lori Ann Mayfield
}

scholarly project submitted in partial fulfillment of the requirements for the degree of Doctor of Nursing Practice

Rocky Mountain University of Health Professions

2018

\section{Volume 2 Issue 6}

Received Date: November 06, 2018

Published Date: December 13, 2018

DOI: $10.23880 /$ nhij-16000165

Published by

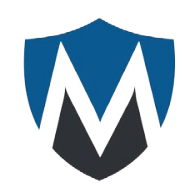

MEDWIN PUBLISHERS

Committed to Create Value for Researchers 


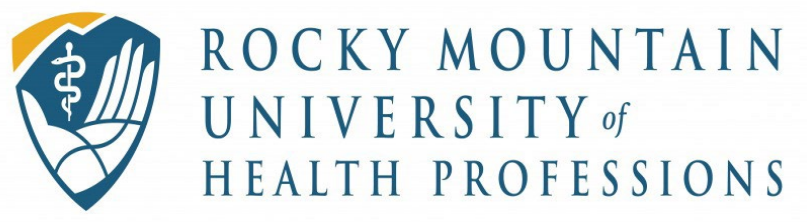

We certify that we have examined the Scholarly Project of:

\section{Lori Ann Mayfield}

And hereby approve it as being complete and meeting partial fulfillment of the requirements for the Doctor of Nursing Practice as recommended by this Scholarly Project Committee:

Faculty Chair: Janet K. Noles

Janet K. Noles, PhD, RN, FNP-BC, FAANP

Content xpert: Amy Christensen

Amy Christensen, MSN, RN, NE-BC

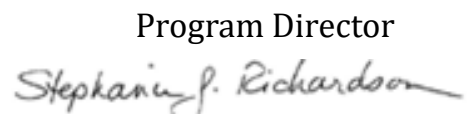

Stephanie J. Richardson, PhD, RN

Month and Year of Approval: April 2018

In presenting this scholarly project in partial fulfillment of the requirements for the Doctor of Nursing Practice degree at Rocky Mountain University of Health Professions, I agree that the Library shall make it copies freely available for inspection. I further agree that extensive copying of the scholarly project is allowable for scholarly purposes, consistent with "fair use" as prescribed by the U.S. Copyright Law. Any other reproduction for any purposes or by any means shall not be allowed without my permission.

Signature

Date: April 20, 2018

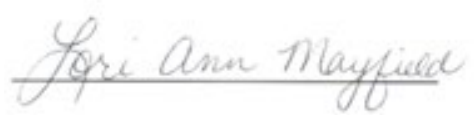




\section{Table of Contents}

Executive Summary

Background
Foreground
EBP Framework
Methods
Findings/Results
Conclusion/Recommendations

Problem

6

Background

6

Local

7

Global Perspective

Theoretical Framework

Evidence-Based Practice Model

7

Methods

8

Settler Model Step 1: Preparation

PICOT

8

Population

Intervention

Comparison

Outcome

Time

Population/Participants

Intervention

Comparison

8

Outcome

8

Time

8

Purpose and Scope

Influence

Internal Review Board Approval

Human Subject Protection

Academic

Institutional

Settler Model Step 2: Validation (Literature Review)

Conflict

Conflict in Healthcare 
Conflict Resolution/Collaboration

Conflict Resolution Education

Theory

11

Model

11

Conclusion of Literature Review

Stetler Model Step 3: Comparative Evaluation/Decision Making

Readiness for System Change

Strategic Plan of the Organization

11

Change Agents

12

Champions

12

Opinion Leaders

12

Stakeholders

12

Stetler Model Step 4: Translation/Application

12

Implementation Strategies and Plans

12

Intervention

13

Outcome Measures

14

Test, Tools, Surveys, and Interviews

14

Stetler Model Step 5: Evaluation

14

Data Collection

14

Level of Change

14

Limitations

14

Conclusion

14

Acknowledgements

15

Dedication

15

References

15 


\section{Effect of Conflict Resolution Education on Nurse-Nurse Collaboration in a Community Hospital Setting}

Keywords: Conflict; Nurses; Healthcare settings; Healthcare; Education

\section{Executive Summary}

\section{Background}

"Conflict is inevitable in a dynamic organization" such as healthcare [1]. Conflict is also associated with significant costs [2]. Conflict affects patient care, job satisfaction, and adds to increased job stress, even rolling over in to affecting family life [3]. Collaboration, on the other hand, improves morale, decreases stress, and increases patient safety [3]. Conflict resolution education can provide nurses with the skills and tools necessary to effectively resolve conflict and increase collaboration.

\section{Foreground}

In the facility in which the scholarly project was conducted, there is no conflict resolution education provided to employees. The closest training received is Zero Harm, an error prevention technique initiative. This initiative was incorporated in to the scholarly project, as conflict resolution can be seen as a potential for harm to patients if not handled effectively.

\section{EBP Framework}

The Stetler Model of evidence-based practice and Hildegard Peplau's theory of interpersonal relationships were used as frameworks for this project. The Stetler model "examines how to use evidence to create formal change within organizations" [4]. Peplau's theory of interpersonal relationships aligned well with this project, as the end result of any conflict in nursing is better patient care, which is a "common goal" of all health care providers, patients, and families [5].

\section{Methods}

The objective of this project was to provide education and tools to nurses to enable them to be able to more effectively resolve conflict and increase collaboration. The education was provided via power point presentation. The pre-education and post-education assessments showed a positive outcome and increase in collaboration.

\section{Findings/Results}

Bushardt, et al. [1] pointed out that it is not "desirable" to "eliminate conflict," rather to "handle it effectively and positively." The results of the project indicated that conflict resolution education improves collaboration among nurses.

\section{Conclusion/Recommendations}

There is "a need to develop nurses' conflict management skills to ensure that conflicts are resolved constructively" [3]. It is recommended that conflict resolution education be provided to increase collaboration between nurses.

"Conflict is inevitable in a dynamic organization" [1]. In the facility in which the project was implemented, there is currently no conflict resolution education provided to nurses. Overton, et al. [2] pointed out that "conflict is associated with significant cost to organizations." Conflict resolution and collaboration go hand-in-hand; "Although collaboration is a time-consuming process, it's an integrated approach and a long-term resolution of conflict" [6]. Therefore, the question arises: Does conflict resolution education increase nurses' knowledge level in resolving conflict and improve collaboration amongst nurses?

\section{Problem}

Healthcare is definitely a dynamic organization. Nurses participate in a variety of "professional roles in their collaborations with patients, other healthcare professionals, families, and healthcare organizations" [3]. Therefore, nurses experience multiple opportunities for conflict to arise.

\section{Background}

Conflict is often seen as a negative event, however conflict resolved in an effective and efficient manner can have a positive impact on an organization, as well as on the parties involved [7]. Conflict management education can help nurses understand that not all conflict is negative, as well as provide tools too effectively and efficiently manage conflict, and increase nurse-nurse collaboration.

\section{Local}

The current problem at the facility where the project 
was implemented is a lack of education regarding effective conflict management skills among nurses. As a previous floor nurse, and as a current nurse manager, the project manager is aware of much of the conflict that arises not only in my own department, but throughout the hospital as well. Conflict "can directly affect nurses' levels of job stress and satisfaction" [3]. Therefore, being able to effectively manage conflict can improve job stress and job satisfaction.

\section{Global Perspective}

According to the World Health Organization (WHO) [8], "nursing encompasses autonomous and collaborative care." Effective conflict management can lead to increased morale, increased confidence, increased communication, and overall increased patient satisfaction. Additionally. Ylitörmänen, et al. [3] shared, "the healthcare environment is constantly changing and collaboration between nurses is becoming ever more important for meeting the needs of the population and enduring patient safety" (p. 264). This is not a localized issue affecting the project implementation facility alone; this is an issue affecting nursing in general.

Additionally, Overton, et al. [2] shared that the impact of conflict on one's "mood is significant," sharing that a realtime study was conducted and the "negative interactions affected the employee's mood five times more strongly than positive encounters". Overton, et al. [2] also shared a study from 2008 that indicated "the number of hours spent per week on workplace conflict [in the United States] was 2.8 hours" with an estimated " $\$ 359$ billion in lost time".

\section{Theoretical Framework}

Peplau's theory of interpersonal relationships provides the theoretical framework for this project [5]. The framework consists of four phases: Orientation, identification, exploitation, and resolution [5].

During the orientation phase, the problem is identified, as well as the "type of service needed;" this phase is essentially the "assessment" phase [5]. During this phase, the nurses were oriented to the scholarly project. The nurses were provided with statistics that supported the fact that "conflict is inevitable" in a dynamic organization such as healthcare [1]. The nurses were also oriented to the specific steps of the scholarly project.

The identification phase is the phase in which a plan is developed once the "appropriate assistance" is identified [5]. This is the phase in which the nurses received the statistics and explanation regarding the need for nurses specifically to have conflict resolution education, and how it would be beneficial.
The exploitation phase requires examining the "problemsolving alternatives" that are to be provided [5]. In this phase of the project, the education and tools regarding conflict resolution were provided via an educational power point presentation at a mandatory staff meeting.

The resolution phase is the "termination of the relationship." [5]. In regards to the scholarly project, this is the phase in which education was provided focusing on the need to move on once the conflict is resolved. In order for the conflict resolution to be considered effective, there must not be any residual feelings of frustration, anger, etc.

Nursing is "an interpersonal process because of the interaction between two or more individuals who have a common goal" [5]. Peplau's theory of interpersonal relationships aligned well with the need for nurses to be able to resolve conflict effectively, as the end result of any conflict in nursing is better patient care, which is a "common goal" of all health care providers, patients, and their families.

In the map found in Appendix A, the blue boxes identify the various phases of Peplau's Theory of Interpersonal Relationships, and the corresponding white boxes identify the strategies of the scholarly project as it pertains to Peplau's theory.

\section{Evidence-Based Practice Model}

The Stetler Model of evidence-based practice provides the framework for this project. According to Cheryl Stetler, the model is useful for "all forms of practice, i.e., educational, clinical, managerial, or other". The National Collaborating Centre for Methods and Tools [4] shared that the Stetler model "examines how to use evidence to create formal change within organizations," as well as "provides a way to think about the relationship between research use and evidence-informed practice.

The Stetler Model includes five phases: preparation, validation, comparative evaluation/decision making, translation/application, and evaluation [9]. See Appendix B for permission to use the Stetler Model. See Appendix C for the Stetler Model algorithm. The Stetler Model served as a framework to effectively guide each phase of the scholarly project.

Liao, et al. [10] indicated that collaboration and teamwork is an indication of nursing ability, which if increased, will improve the work environment and result in improved patient safety and health. Bushardt, et al. [1] shared results of a study which indicated that withdrawal is the most common approach to conflict among nurses, and that it is important to seek resolution of conflict in a constructive manner, not 
to avoid it. Conflict among nurses can lead to a number of negative consequences within the profession, including decreased morale, weakened relationships, and patient needs not being met among other things [11]. Educating nurses on conflict resolution strategies can provide them with the tools and confidence they need to effectively resolve conflict and improve collaboration.

\section{Methods}

The methods used to guide this project include the five steps of the Stetler Model of Evidence-based Practice. Each of the steps involved were reviewed and considered throughout the entire project. This model proved to be helpful throughout the entire process.

\section{Settler Model Step 1: Preparation}

The first step in the Stetler Model is preparation, which involved identifying the problem, searching articles, and identifying measurable outcomes regarding my topic of conflict resolution education. This step was completed by creating a PICOT (Population, Intervention, Comparison, Outcome, Time frame) question, stating the purpose, scope, and influence of the project. Finally, Institutional Review Board (IRB) approval had to be obtained at the academic and institutional levels.

\section{PICOT}

\section{Population}

RNs on the Cardiovascular/Neurological Unit.

\section{Intervention}

Conflict Resolution Education.

\section{Comparison}

Pre-education assessment versus post-education assessment

\section{Outcome}

Increase in collaboration between RNs.

\section{Time}

14 days between assessments

\section{Population/Participants}

The population for this project included Registered Nurses (RNs). The RNs asked to participate were employed on the Cardiovascular/Neurological Unit of a community- based hospital. There were approximately 50 RNs employed on the unit at the time of project implementation. A total of 35 RNs completed the pre-education assessment, and 6 RNs completed a post-assessment survey.

\section{Intervention}

The project manager presented a 15-minute power point presentation to the RNs who choose to participate. The power point presentation included a definition of conflict, various conflict management styles, and tools that can be used to effectively handle conflict.

\section{Comparison}

The project manager provided an established assessment tool, before and after the educational power point. The tool is both valid and reliable and was used to measure collaborative behaviors among RNs. The tool used was the Nurse-Nurse Collaboration Behavior Scale [10]. See Appendix D for the Nurse-Nurse Collaboration Behavioral Scale.

\section{Outcome}

The outcome measure for this project was the nursenurse collaboration assessment, which was provided before and after receiving conflict resolution management education. The outcome indicated an increase in collaboration between the RNs, with each of the post-surveys showing a positive increase in collaboration.

\section{Time}

The pre-education assessments were provided at the time of the education. The post-educational assessments were also provided at the time of the education with instructions to complete the assessment after a 14-day-period.

The pre-education assessments were collected at the time the education was provided. The post-education assessments were to be completed 14 days after the education was provided. The project manager went to CVNU to collect the assessments from the nurses that participated between days 14 to 20 . This provided time for nurses that were on days off to turn in their assessments.

\section{Purpose and Scope}

The purpose and scope of this project was to provide conflict resolution education in an effort to increase the collaboration between the RNs on the Cardiovascular/ Neurological Unit. With conflict resolution education, and specific tools which were included in the education, the 
nurses are better prepared to enter in to a potential conflict with confidence, having been provided the tools necessary to turn conflict in to collaboration.

The purpose of the tools provided was to keep it simple, and to include tools the nurses are already familiar with in order to make the implementation a smooth process. Being that this is a change at the unit level, and with a focus on only one discipline, this project is an incremental change process.

\section{Influence}

Providing conflict resolution education may have a positive influence on the collaboration between nurses. Collaboration is a characteristic of a "professional practice environment," as well as influence a "units' ability to work effectively" [11]. Siu, et al. [11], support the positive impact conflict resolution can have with the statement, "effective conflict management skills have been identified as a necessary competency for nurses to deliver safe, highquality care in today's complex healthcare system (p. 250). The idea that increased collaboration can lead to safer care is an important sphere of influence.

\section{Internal Review Board Approval}

\section{Human Subject Protection}

The participant's rights were protected by keeping their identity confidential. The pre- and post-education assessments were assigned corresponding numbers to protect the participants identity-no names were provided. Additionally, the assessments were provided in a random order as well to protect the identity. In addition, the project leader completed a Human Rights Protection course through the Collaborative Institutional Training Initiative (CITI Program). See Appendix E for the CITI Certificate.

\section{Academic}

A thorough application was completed and provided to the academic institution prior to the implementation of this project. The IRB application was found to be appropriate for an expedited review and was approved. See Appendix F for academic IRB approval

\section{Institutional}

A thorough application was completed and provided to the institution prior to the implementation of this project. The IRB application was found to be appropriate for an expedited review and was approved. See Appendix G for institutional IRB approval.

\section{Settler Model Step 2: Validation (Literature Review)}

The second step in the Settler model was assuring that each article chosen to support my project was valid and reliable, and included effective and relevant information relating to the project. Several articles were discovered that proved to be reliable and have valid research results completed this step. The articles discovered had high relevance to the topic.

The review of literature involves the first three steps of the Settler Model: preparation, validation, and comparative evaluation/decision making. The literature review focuses on the question: Does conflict resolution education increase collaboration between nurses? The literature indicates that conflict is inevitable in general, and is only increased in the health care environment. However, if handled effectively, conflict can be a positive experience, instead of the negative experience it is anticipated to be by so many. In the recent decades, conflict resolution training is becoming more evident as a necessary element in the health care profession.

The search methods included searching databases which included: Google Scholar, OVID, and EBSCO, which includes: CINAHL complete, EBMR, Education Research Complete, HaPI, Medline Complete, Pysch INFO, Psyc TESTS, and SPORT Discus. The MeSH terms used included: conflict management, conflict resolution, conflict in healthcare, conflict resolution in healthcare, conflict management in healthcare, conflict resolution education.

The topic of conflict resolution has been well-researched. To narrow down the literature search, the terms health care and education were included in the search of conflict resolution. The topic of education regarding conflict resolution in healthcare proved to narrow the search, however it still provided a great deal of information. As previously stated, conflict is inevitable, which helps explain why there is so much information on the subject.

\section{Conflict}

Conflict is often seen as negative. Leever, et al. [12], shared that conflict is viewed as "seriously negative events, ranging from an atmosphere of discord to a state of affairs where working together is no longer possible" (p. 617). Adding to this view, Merriam-Webster defines conflict in one of three ways: "1) fight, battle, war, 2a) competitive or opposing action of incompatibles: antagonistic state or action (as of divergent ideas, interests, or persons), 2b) mental struggle resulting from incompatible or opposing needs, drives, wishes, or external or internal demands, and 
3) the opposition of persons or forces that gives rise to the dramatic action in a drama or fiction" $(2017, \mathrm{np})$. With definitions such as these, it is easy to see why conflict can be viewed as a negative.

However, Higazee [13] pointed out that conflict can be seen as either negative or positive, as well as dysfunctional or healthy; it can be positive and healthy if handled correctly. McKibben [14] shared that conflict can be positive if resolution is getting down to the root causes of the conflict and addressing them (p. 100). Conflict can have the following benefits: improved understanding, development of the team, and improved quality in decision making among groups [2]. Bushardt, et al. [1] pointed out that it is not "desirable" to "eliminate conflict," rather to "handle it effectively and positively."

\section{Conflict in Healthcare}

Due to the variety of roles that nurses play, coupled with the human interactions that take place in hospitals, the probability of conflict is significantly increased [13]. Adding to the variety of roles nurses play, are the various departments and hierarchy of positions that can complicate the issue. In a study completed at Gundersen Lutheran Health System in LaCrosse, et al. [15] reported that "In general nurses would rather avoid conflict". The issue of avoidance is due to the fact that they don't "intuitively" know hand to handle it [15]. Trossman [15] added that conflict in the healthcare arena can cause patient care to suffer. Siu, et al. [11] pointed out that persistent conflict among nurses is destructive and can lead to decreased morale, weakened relationships, limited communication, and a delay in patients needs.

Ylitörmänen, et al. [3] pointed out that the "health care environment in constantly changing" and therefore "collaboration" is becoming increasingly important in order to ensure the safety of the patients.

Leever, et al. [12] also shared that in recent decades, the need for collaboration (conflict resolution) for health care professionals has been growing. Conflict is a daily occurrence for those in the healthcare profession [6].

\section{Conflict Resolution/Collaboration}

Collaboration and conflict resolution were used interchangeably in the literature. Leever, et al. [12] pointed out that conflict resolution is complex, and generally not something that is "self-generated". Bushardt, et al. [1] shared that conflict resolution, when effective, can "enhance the functioning of organizations. McKibben [14] complimented Leever, et al., when sharing that effective conflict resolution, if managed well, can be beneficial".
McKibben [14] reported, "conflict resolution seeks to solve a problem, not the person, therefore condemning individuals is not the solution". This is an important piece of educating nurses on effective conflict resolution. If conflict is looked at as a problem to be solved, instead a person to condemn, the negative association tied to conflict can begin to dissolve. Siu, et al. [11] pointed out that nurses are professionals and therefore "are expected to resolve conflict in practice". Additionally, Siu, et al. [11] shared that effective conflict resolution skills are necessary to enable them to provide the safe and high quality care needed today.

Liao, et al. [10] shared that "collaboration and strong communication among nurses" is a critical component to providing and "maintaining a safe and therapeutic environment for patients". A lack of collaboration has also been found to be a "primary contributor" to adverse event, medical errors, and delays in treatment [10]. A key factor in collaboration is that the parties involved are "working towards a common goal" [12]. In the Liao, et al. [10] study, 202 nurses completed a survey regarding nurse-nurse collaboration. This number represented a $95.05 \%$ response rate. The results of the survey indicated there are four factors demonstrated by nurses that collaborate effectively, which are: common goals, conflict management, professional interactions, and cooperation [10].

\section{Conflict Resolution Education}

Established guidelines and the use of effective conflict resolution strategies will enable nurses to have positive work outcomes by implementing effective conflict resolution [11]. Results of a 2006 research study examining how nurses interact with other members of the health care team suggested that nurse leaders establish structures and policies encouraging environments that "exemplify collaboration, credibility, compassion, and coordination among team members" [16]. Although not directly tied to conflict resolution specifically, these factors can be helpful in educating nurses in effective conflict resolution. Nurses are "legally accountable for providing competent care, and is ethically bound to the non-maleficence principal," therefore, it is a nurses "duty and obligation" "to prevent or resolve conflict, and promote the health and wellbeing of patients" [14].

Moisoglou, et al. [6] found that $65.6 \%$ of nurses in their research did not have any type of training in conflict resolution, which "highlights the education gap in conflict management". Overton, et al. [2] pointed out that "evidence suggests the skills for effective management of conflict can be learned". Trossman [15] shared that after 300 nurses completed a conflict resolution education program, "participating nurses had a real desire to quit creating workarounds to avoid 
conflict because they had stronger skills to comfortably and respectfully address it". Lastly, Bushardt, et al. [1], indicated that "conflict resolution training should be made available to nurses on the job through some form of in-service or continuing education program".

\section{Theory}

Hildegard Peplau's theory was published in 1952 and 1968 [5]. The theory is comprised of "four sequential phases in the interpersonal relationship: orientation, identification, exploitation, and resolution" (2016). The orientation phase defines the problem; the identification phase develops a plan; the exploitation phase involves communication; and the resolution phase is the termination of the relationship (2016)

\section{Model}

The Stetler Model includes five phases: preparation, validation, comparative evaluation/decision making, translation/application, and evaluation [9]. According to Cheryl Stetler, the model is useful for "all forms of practice, i.e., educational, clinical, managerial, or other". The National Collaborating Centre for Methods and Tools (2017) shared that the Stetler model "examines how to use evidence to create formal change within organizations," as well as "provides a way to think about the relationship between research use and evidence-informed practice."

\section{Conclusion of Literature Review}

Conflict resolution education, if conducted properly, can provide nurses with the skills and tools they need to effectively resolve conflict in the many roles they play in any given day. Conflict is a part of life, and for many nurses, a part of life they would prefer to avoid. The literature suggests that effective conflict resolution can not only be beneficial for the nurse and co-workers, but also help the nurse to deliver greater patient care. A big part of effective conflict resolution education is communication; a great quote shared by Overton and Lowry [14] is: "Speak when you are angry and you will make the best speech you will ever regret - Ambrose Bierce". Effective conflict resolution education will help nurses to avoid making "the best speech [they] will ever regret."

\section{Stetler Model Step 3: Comparative Evaluation/Decision Making}

The third step in the Stetler model includes evaluating and making decisions regarding the project. These items included the systems readiness for change, the strategic plan of the organization, and the individuals involved in the project, such as key stakeholders and champions.

\section{Readiness for System Change}

The Chief Nursing Officer, via verbal conversations regarding the project, expressed her willingness to serve as the clinical advisor to the project leader, thus, supporting readiness for system change at the facility level. The philosophy of Zero Harm, as well as the mission, vision, and values of the organization, also support the readiness for system change.

Zero Harm is a continuous improvement patient safety initiative implemented organization-wide in 2016 (Intermountain Healthcare). The Zero Harm initiative is an error prevention training that includes specific techniques to properly communicate with team members $[17,18]$. See Appendix $\mathrm{H}$ for an example of the Zero Harm Error Prevention Techniques. The Zero Harm initiative supports the conflict resolution education included in this project as part of the system readiness for change. The article by Liao, et al. [10], which includes the scale used for the outcome measure of this project, supports the relationship of conflict resolution education and the Zero Harm initiative. Liao, et al. [10] explained that the sub-construct of collaboration, which is the result of conflict resolution, "contribute[s] to the positive outcome in reducing adverse events."

\section{Strategic Plan of the Organization}

The mission, vision, and values of the organization in which the project took place, support the readiness for the system change. See Appendix I for the mission, vision, and values of the organization in which the project took place. The strategic plan of the organization is in line with the system readiness for change in regards to the philosophy and values of the organization. Beginning with the first fundamental of extraordinary care found on the mission, vision, and values of the organization-safety $[17,18]$. The fundamental of safety indicates, "patients and caregivers experience Zero Harm" $[17,18]$. As previously mentioned, the Zero Harm initiative embodies error prevention techniques, and conflict resolution, thereby resulting in collaboration, and helps to reduce medical errors [10]. Another fundamental of extraordinary care is that of engaged caregivers $[17,18]$. The engaged caregivers fundamental indicates, "caregivers have an unparalleled work experience that supports them in delivering the fundamentals of extraordinary care" $[17,18]$. Conflict resolution supports this element of the organizations strategic plan in that the result of successful conflict resolution is increased job satisfaction and the ability to maintain "a safe and effective therapeutic environment for patients" [10]. 


\section{Change Agents}

The change agents for this project included the project manager, the scholarly project clinical content expert and the scholarly project faculty chair. The project manager compiled, led, and educated a group of champions, opinion leaders, and staff members on the content of the project. The project manager did this while maintaining the integrity of the university, as well as embodying the mission, vision, and values of the institution. Additionally, the project manager was responsible for assuring the validity of the information provided, as well as maintaining the confidentiality of the participants, distributing the surveys, providing the education, collecting the data, analyzing the data, and providing the results in aggregated fashion to those involved.

The scholarly project clinical expert was the Chief Nursing Officer of the facility; she recognized the significance of the project, and willingly offered her time and support as a change agent to this project. Through her experience and expertise, she was able to provide excellent advice, opinions, feedback, and support during the creation, implementation, and conclusion of the project. Additionally, she was instrumental in the approval of the IRB process at the organizational level.

The scholarly project faculty chair was an instrumental change agent to this project. She offered her feedback, advice, and support via weekly conference calls, as well as being available for communication at many other times. This mentor was instrumental in developing the project, assisting with finding proper outcome measure tools, developing data collection tools, and facilitating the IRB approval at both the institutional and university level.

\section{Champions}

Champions for this project included the cardiovascular/ neurological unit manager, director of the cardiovascular service line, the facility chief nursing officer, and the regional chief nursing officer. Each of these champions was instrumental to the success of the project.

The director of the cardiovascular service line and the regional chief nursing officer were champions in supporting the implementation of this project. The facility chief nursing officer was a champion in her support and expert advice for the project. The cardiovascular/neurological unit manager was imperative to this project, as he allowed the project manager to use his unit as the base for the education and implementation of the project. The manager voluntarily provided time at two staff meetings to allow the project manager to conduct the conflict resolution education and distribute the initial surveys to the nurses on his unit. The manager also allowed the project manager to come to his unit to collect the post-surveys.

\section{Opinion Leaders}

The opinion leaders for this project included the cardiovascular/neurological unit manager, the charge nurses on the cardiovascular/neurological unit, and the cardiovascular/neurological unit educator. They were each instrumental in providing support to the project manager and encouraging the front line staff nurses to participate in the project.

\section{Stakeholders}

The faculty chief nursing officer, cardiovascular/ neurological unit manager, and cardiovascular/neurological unit nurses were key stakeholders in the project. Each of these stakeholders were involved in communication, with the faculty chief nursing officer and cardiovascular/ neurological unit manager, involved in the development of the education for the staff nurses and the relationship of the conflict resolution education with the organizational Zero Harm initiative. Whereas the cardiovascular/neurological unit nurses were key stakeholders as the individuals that completed the pre-surveys, accepted the education, and completed the post-surveys.

\section{Stetler Model Step 4: Translation/ Application}

This step of the Stetler model included implementation strategies and plans, as well as the actual intervention of using information obtained in the first three steps to create the pre- and post-surveys and educational power point. Additionally, during this step, the assessments were completed by the RNs, as well as the conflict resolution education being provided by the project manager. This step included the tests, tools, surveys, and interviews that needed to take place.

\section{Implementation Strategies and Plans}

The implementation strategies and plans took place over a period of several months.

May 2017

- Begin collecting literature to support project.

- Begin searching for a valid and reliable tool to use for assessment.

- Complete CITI modules for IRB process. 
June 2017

- Select Scholarly Project content expert at institutional level.

- Obtain signed agreement from Scholarly Project content expert at institutional level.

- Select EBP Model to use for project.

- Continue collecting literature to support project.

July 2017

- Obtain signed agreement from of institutional support.

- Obtain copyright approval to use EBP model.

- Evaluate literature to use in project.

August 2017

- Present project to Cardiovascular/Neurological Nurse Manager.

- Obtain approval from Cardiovascular/Neurological Nurse Manager to implement on his unit.

- Complete educational power point to present.

- Complete invitation to participate letter.

September 2017

- Complete academic IRB application.

- Submit academic IRB application.

- Obtain academic IRB approval.

- Complete institutional IRB application.

- Submit institutional IRB application.

- Obtain institutional IRB approval.

- Provide invitation to participate letter to Cardiovascular/ Neurological Unit manager.

- Implement Project on the Cardiovascular Unit.

- Collect pre-educational assessments.

October 2017

- Collect post-educational assessments.

- Compile results of pre- and post-assessments.

- Input results in to data collection tool.

- Provide aggregate data to Cardiovascular/Neurological Manager.

\section{Intervention}

Moisoglou, et al. [12], included information from the American Association of Critical-Care Nurses (AACN), which indicated that the AACN "included true collaboration among six essential standards for establishing and sustaining a healthy work environment". Step one of the intervention included a flyer that was provided to the Nurse Manager of the Cardiovascular/ Neurological Unit (CVNU) to educate the nurses regarding the scholarly project and request their participation. The flyer was provided approximately one month prior to the implementation of the project. The nurses were further informed about the project during a staff meeting, at which time the RNs were given the opportunity to participate, or not, which served as their implied consent.

Following the information regarding the project, the project manager provided an established assessment tool that is both valid and reliable, to measure collaborative behaviors among RNs. The assessment tool used was the NurseNurse Collaboration Behavior Scale [10]. The assessment tool consisted of 23 questions, consisting of 4 categories: conflict management, common goals, communication and coordination, and professionalism and autonomy [10]. The reliability of the tool is evidenced by a Cronbach's coefficient of 0.929 and the test-retest correlation coefficient for the overall tool was 0.764 [10].

The Nurse-Nurse Collaboration Behavior Scale provided participants with the opportunity to indicate their level of agreement with specific statements regarding conflict. The scale provides five options with corresponding points to choose from: Always ( 5 points), Usually (4 points), Sometimes ( 3 points), Rarely ( 2 points), and Never ( 1 point). Using the points correlated to each answer, the pre-education and post-education assessments of each participant were tallied and entered in to the data collection tool. The data collection tool was designed to demonstrates the difference between the pre- and post-assessment scores automatically.

Following the completion of the assessment tool, a 15-minute power point presentation developed by the project manager was presented to the RNs who choose to participate. Included in this power point presentation was a definition of conflict, various conflict management styles, and tools that can be used to effectively handle conflict. A new initiative entitled Zero Harm relating to patient safety has been established at the facility, and was taught to all current employees and affiliates. Zero Harm provides employees with specific tools to effectively voice a concern as it relates to patient safety, however it does not address conflict specifically.

The tools included in the power point included tools researched and found in peer-reviewed articles/studies, as well as the facilities tools implemented in the Zero Harm initiative. The post-assessment tool was provided at the time the original assessment tool was provided and the educational power point presentation was conducted. This post-assessment survey was provided to evaluate the effectiveness of the teaching; thereby measuring whether or not the RNs level of collaboration improved.

\section{Outcome Measures}

Increasing knowledge regarding conflict management, and providing tools for effective conflict management, can have a positive impact on an organization and the 
parties involved. Such knowledge can increase morale and decrease costs. Ylitörmänen, et al. [3] concluded that "RNs should be given clear instructions on how to deal with conflict situations" and that nurses need to develop "conflict management skills to ensure that conflicts are resolved constructively". The outcome measure for this project was the nurse-nurse collaboration assessment, which was provided before and after receiving conflict resolution management education. The RNs were asked to complete the postassessment 14 days after the education was provided, and the pre-assessment was completed. An additional potential future outcome measure(s) could be the collaboration between various disciplines after having received the same education.

\section{Test, Tools, Surveys, and Interviews}

No tests were used during this project. The tool used for this project was the Nurse-Nurse Collaboration Behavioral Scale (see Appendix D), which was also the assessment/ survey. No interviews were conducted for this project.

\section{Stetler Model Step 5: Evaluation}

During this step, the pre-and post-assessment results were input in to a data collection tool created by the project manager. The results were then compared and evaluated for improvement of collaboration. The results were evaluated for significant evidence to implement a level of change. The limitations were also considered during this phase.

\section{Data Collection}

The data was collected via the pre- and post-assessment surveys. The survey's results were summed and input in to a data collection tool. The tool was created to show the difference between the pre- and post-assessments. A positive number indicated a positive change, or improvement in collaboration, whereas a negative number indicated a negative change, or decrease in collaboration. See Appendix J for the completed data collection tool.

\section{Level of Change}

The 14-day post-survey results of the project showed an increase in collaboration amongst the RNs due to effective conflict management. All 6 of the post-assessments were positive for an increase in collaboration amongst the RNs. The score increases ranged from a positive difference of 2 to 25 points, with a mean increase of 14 points. The results have been provided to the Nurse Manager of the Cardiovascular/ Neurological Unit, as well as the Chief Nursing Officer.
With positive results, there is a possibility that the level of change will be escalated to a facility level to provide conflict resolution education to all employees. If the facility level proves to be successful, the ultimate level of change would be that of a system implementation of providing conflict resolution education to all members of the system.

\section{Limitations}

Limitations included presenting the educational power point and handing out the assessments at a staff meeting that was not deemed as mandatory, thereby limiting the number of RNs present. A second limitation included having another presenter attend the staff meeting and present prior to the project manager, thus leading to possible fatigue on the part of the RNs. A third limitation was the lack of engagement by the RNs during the educational power point. A fourth limitation included the lack of post-assessment survey responses. Lastly, a fifth limitation included the perception of what conflict is, and the possibility of the staff not understanding the purpose of the project.

\section{Conclusion}

There is "a need to develop nurses' conflict management skills to ensure that conflicts are resolved constructively" [3]. From the limited assessments that were returned, the outcome was a positive change in nurse-nurse collaboration. Due to this finding, the nurse manager of the unit educated will continue to educate new hires to the unit, as well as implement the training on an annual basis.

Increased nurse-nurse collaboration improves morale, decreases stress, and increases patient safety [3]. Providing this conflict resolution education provided the nurses on the involved unit with the skills and tools necessary to effectively resolve conflict. This education will also have the potential to improve the unit to be representative of a "professional practice environment," as well as influence the nurses on the unit to increase their ability to work effectively" $[11,19,20]$.

As the organization is currently undergoing a structure change of the senior leadership, the implementation at the facility, and potentially the organizational level, will be on hold for now. However, suggestions for future work include implementation of an additional assessment on another unit that may be more engaged. An additional suggestion would be to implement the education and assessment outside the scope of nursing, within other disciplines (i.e. respiratory therapy, dietary, maintenance, housekeeping, etc.), as well as across disciplines (i.e. nursing/respiratory therapy, nursing/ dietary, maintenance/housekeeping, etc.). 


\section{Acknowledgements}

I would like to acknowledge those who have attended this scholarly project and presentation of such. Those individuals include Dr. Stephanie Richardson, Dr. Janet Noles, Dr. Kevin Ballard, Amy Christensen, and Mark Seegmiller.

I would like to extend my appreciation for the time, effort, patience, support, and expert advice provided that has made this scholarly projects a success. I would like to express gratitude to Dr. Noles for her weekly calls to check the status of my project, answer my questions, provide expert advice, and provide support during each phase of the project. Her dedication as a professor and academic advisor is unwavering and helped with the success of this project.

\section{Dedication}

I dedicate this project first and foremost to my Father in Heaven, and to my Savior, Jesus Christ, for the opportunities afforded to me in my life. There were many prayers seeking guidance, comfort, and strength during this process; I could not have endured this journey without those prayers being answered. I am eternally grateful for the blessings in my life, especially my eternal companion, and my eternal family.

I lovingly dedicate this project to my eternal companion and best friend, Scott Mayfield, for his undying dedication, unwavering support, limitless patience, and most of all, his compassionate love. His knowledge of just what I needed, exactly when I needed it has uplifted me and kept me going at the toughest times; whether it was a bag of skittles, a quick break to eat, or simply a hug. He is truly my biggest fan, and I his.

I also dedicate this project to my children and grandson (and future grandchildren): Andrew, Kayla, Jacob, Meghan, Alyssa, and Wake. All of who graciously understood when I could not attend special events due to my academic pursuit. I pray that the hours spent studying, and the evident growth academically, emotionally, and spiritually throughout my education pursuits will be an example to each of you to set goals and do all that you can to achieve them. My hope is that each of you see the value in lifelong learning.

To all of my parents and siblings...thank you for your support during this journey. Especially to Jennifer and Chandler for opening your home and arms to me during each on-site visit, and for listening to me vent, cry, and celebrate during my time in your home. I am especially grateful to have had the opportunity to watch your family grow, and to spend precious moments with Kellin, Blakely, and Scottie over the past few years.

\section{References}

1. Bushardt SC, Fowler AR, Jones MA (1993) Retaining nurses through conflict resolution. Training staff to confront problems and communicate openly can improve the work climate. Health Prog 74(5): 25-29.

2. Overton AR, Lowry AC (2013) Conflict management: difficult conversations with difficult people. Clinics in Colon and Rectal Surgery 26(4): 259-264.

3. Ylitörmänen $T$, Kvist $T$, Turunen $H$ (2015) A webbased survey of Finnish nurses' perceptions of conflict management in nurse-nurse collaboration. International Journal of Caring Sciences 8(2): 263-273.

4. National Collaborating Centre for Methods and Tools (2011) Stetler Model of Evidence-based Practice. Hamilton, ON: McMaster University.

5. Hildegard P (2016) Nursing theory.

6. Moisoglou I, Panagiotis P, Galanis P, Siskou O, Maniadakis $\mathrm{N}$, et al. (2014) Conflict management in a Greek public hospital: Collaboration or avoidance. International Journal of Caring Sciences 7(1): 75-82.

7. Choi Y (2013) The influence of conflict management culture on job satisfaction. Social Behavior and Personality: An international journal 41(4): 687-692.

8. WHO (2018) Health topics: Nursing. World Health Organization.

9. Romp CR, Kiehl E (2009) Applying the Stetler Model of research utilization in staff development: Revitalizing a preceptor program. J Nurses Staff Dev 25(6): 278-284.

10. Liao C, Qin Y, He Y, Guo Y (2015) The nurse-nurse collaboration behavior scale: Development and psychometric testing. J Nurses Staff Dev 2(4): 334-339.

11. Siu H, Spence Laschinger HK, Finegan J (2008) Nursing professional practice environments: Setting the stage for constructive conflict resolution and work effectiveness. The Journal of Nursing Administration 38(5): 250-257.

12. Leever AM, Hulst MV, Berendsen AJ, Boendemaker PM, RoodenburgJL (2010) Conflicts and conflict management in the collaboration between nurses and physicians - A qualitative study. J Interprof Care 24(6): 612-624. 
13. Higazee MA (2015) Types and levels of conflicts experienced by nurses in the hospital settings. Health Science Journal 9(6): 1-6.

14. McKibben L (2017) Conflict management: importance and implications. Br J Nurs 26(2): 100-103.

15. Trossman S (2011) The art of engagement. The American Nurse.

16. Apker J, Propp KM, Zabava Ford, WS, Holfmeister N (2006) Collaboration, credibility, compassion, and coordination: Professional nurse communication skill sets in health care team interactions. Journal of Professional Nursing 22(3): 180-189.

17. Intermountain Healthcare (2017) Mission, vision, values.

18. Intermountain Healthcare (2017) Orientation booklet students in a clinical facility.

19. Choi Y (2013) Social Behavior \& Personality: An International Journal 41(4): 687-692.

20. Conflict (2017) Merriam-Webster.

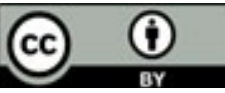

